\title{
Retail potential of districts of Istanbul
}

Received (in revised form): 21 July 2006

\begin{abstract}
Fatih Terzi
is a research assistant in the Department of Urban and Regional Planning at Istanbul Technical University. He has an MSc degree from the Urban Planning Program at Istanbul Technical University. Areas of interest include housing policy, urban renewal and squatter settlements upgrading. His recent research focused on real estate development-housing and retail-and economic growth.
\end{abstract}

\section{Hasan Mutlu}

is a city planner who is experienced in GIS software development. For the past 5 years he has provided consultancy services to local government projects on the effective usage of GIS in urban planning and developed a number of urban mathematical models. He is also involved in Real Estate research with a particular focus on office rent rates and land values in Istanbul.

\section{Vedia Dokmeci}

is a Professor at the Technical University of Istanbul from where she received an engineering/ architecture degree, and subsequently gained an MSc and PhD from Colombia University, New York. She has had several articles published in a number of international journals in relation to location theory, hospital planning, urbanization in developing countries, city systems, factory location, community satisfaction, location of library system, hotels and real estate markets in Istanbul. In 1999 she was given Science Award by the Turkish Academy of Sciences.

\section{Fatih Terzi}

Department of Urban and Regional Planning Faculty of Architecture Istanbul Technical University 34437

Taskisla, Taksim

Istanbul, Turkey

Tel: + 90212 2931300; ext2811

Fax: +90212 2514895

E-mail: terzifati@itu.edu.tr

\begin{abstract}
After 1980 s, globalisation and economic restructuring encouraged the growth of the number of shopping centres in Istanbul. As their number increased, retail market became more competitive, which resulted in a vital need to investigate retail potential of new shopping centre locations. This paper investigates the spatial distribution of existing shopping malls and tries to estimate the retail potential of those districts that do not have any shopping centre yet. Of the 32 districts that make up Istanbul, only 16 have shopping malls. Two historical districts and one summer resort area on the islands are excluded from the analysis. A gravity model is applied to determine the retail potential of the 13 remaining districts that do not have shopping centres yet. Income of the districts, distances to the existing and proposed shopping centres and their sizes are taken as variables in the analysis. According to the results of the study, the districts are ranked with respect to their retail potential. Future research investigating the impact of characteristics of shopping malls and demographic characteristics of consumers and distance on the shopping behaviours of customers would add further value to the research.
\end{abstract}




\section{Keywords:}

shopping malls, retail trade, retail potential, spatial, Istanbul

Journal of Retail and Leisure Property (2006) 5, 314-325.

doi:10.1057/palgrave.rlp.5100035

\section{INTRODUCTION}

Istanbul, being at the intersection of international trade routes and the capital of three empires throughout history, has always had a very large market area and a variety of retail spaces ranging from street shopping to the world famous covered bazaars. In developed countries, the landscape of mass consumption, however, created a metropolitan society in which people were no longer brought together in central marketplaces and streets that surrounded them but, rather, separated by class in differentiated commercial subcentres. ${ }^{1}$ After 1980 s, globalisation and economic restructuring of Turkey increased Istanbul's integration with the world economy ${ }^{2}$ and stimulated the transformation of retail organisation by shifting power from traditional small traders to large domestic and foreign firms. ${ }^{3}$ One of the reasons of the attractiveness of the retail market for large domestic and foreign companies has been the significant increase in per capita income in the country since $1980 \mathrm{~s} .{ }^{4}$ The transfer of western capital and the rapid transmission of the western consumption culture are apparent in different parts of the city. Increasing exposure to other cultures stimulated the growth of a new consumer culture and lifestyle under the influence of global consumption patterns. The spatial expression of this transformation was in terms of large shopping malls that are flourishing throughout the Istanbul Metropolitan area. The shopping malls as a social space provide good opportunities for family use and for people of different age and income groups through the variety in goods availability and services. ${ }^{5}$ Despite the rapid growth of shopping centres in Istanbul, there are still districts that do not have any shopping mall and this study estimates the retail potential of these districts.

Gravity type models are powerful tools in real estate research and particularly used to estimate sales for retail centres. ${ }^{6}$ The principle underlying retail gravity models is that the attractiveness of a retail centre is directly related to its size and inversely related to the distance shoppers must travel to patronise it. ${ }^{7}$ The retail gravity literature has been extensive and essentially based on Newton's Law of Gravitation dated in $1686 .{ }^{8}$ The gravity concept was first applied to retail marketing by Reilly in 1931. ${ }^{9}$ Reilly's Law is used to estimate a market boundary of two towns or cities competing for retail trade. According to Reilly, the delineation of the market boundary is a function of the distance between the towns and their sizes. ${ }^{10}$ The concept of Reilly's law and its derivatives have made significant advances in trade estimation and market-share determination, ${ }^{11}$ sales forecasting techniques ${ }^{12}$ and site selection models. ${ }^{13}$ As one of its earlier extensions, Huff, ${ }^{14}$ in 1966, reformulated Reilly's gravity model in terms of probability and it is widely applied in retail market potential analysis. Huff's model is developed to allow projections of the expected viability of the new centres and their influences on existing centres. It is a 
more sophisticated application of the gravity principle, focusing on the propensity of consumers within various areas to use a particular shopping centre. It assumes that consumers will be able to choose between several competing centres and that their choice will be determined by the size and distance of the centres. ${ }^{15} \mathrm{~A}$ further interesting analysis from the 1960s was Lakshmanan and Hansen. ${ }^{16}$ As an attempt to estimate future shopping potential, they introduced a variable representing the projected retail expenditures in the various residential zones that made up the study area. The analysis focused on examining the long-term stability of location and facility size distribution. For each class of goods, their model assesses levels of turnover per square foot of floorspace as profitability thresholds, plotting these levels for the major centres in the Baltimore region. ${ }^{17}$ The Lakshmanan and Hansen Model had enormous empirical influence, and variations of the framework underpinned numerous regional and subregional shopping models, shopping centre impact studies and retailers' estimates of relative market share. ${ }^{18,19}$

Later, some of the gravity modelers also included a dynamic dimension into their formulation. ${ }^{20,21}$ By the end of 1980s, a wide variety of sophisticated Geographical Information Systems (GIS) databases, containing spatially organised information on store locations, transportation provision, consumer expenditure, etc., were available. ${ }^{22,23}$ To improve the accuracy of the basic gravity model, many researchers included additional variables. Revelle and his co-worker ${ }^{24,25}$ have constructed a group of models to examine competition among retail stores in a spatial market. Drezner, ${ }^{26}$ in 1998 , investigated the location of multiple competing facilities in an area where other facilities already existed. Later, researchers developed interaction models that embraced, among others, store size and location, ${ }^{27}$ and multiple retail organisations. ${ }^{28}$ Multipurpose shopping behaviour of consumers were also incorporated into the model. ${ }^{29} \mathrm{~A}$ comprehensive review of retail location models is given by Brown in $1992 .{ }^{30}$ Moutinho et al. ${ }^{31}$ explore alternative changes that could take place in the technology, methodology and the practice of retail location by the use of artificial intelligence techniques for strategic decision making. Later, Roy et al. ${ }^{32}$ in 2001 presented a simultaneous modelling of multipurpose/multistop activity patterns and quantities consumed. Moreover, the geographic interdependencies of retail market areas are investigated by Mushinski and Weiler in 2002. ${ }^{33}$ Lately, there are also GIS models which are rapidly becoming a popular tool in the retail industry for site location analysis. ${ }^{34}$ Yang $^{35}$ in 2002 analyzed shopping centre location distribution for a small city with respect to its environmental and retail supply quality.

Furthermore, Lee and Pace ${ }^{36}$ examine the distribution of sales for a retail chain using a spatial gravity model. Unlike previous empirical studies, their approach models spatial dependencies among both consumers and retailers. The results show that both forms of spatial dependence exert statistically and economically significant impacts on the estimates of parameters in retail gravity models. The importance of the distance parameter in retail gravity models is greatly understated. Thus, ignoring spatial dependence may lead to an overestimation of the deterministic extent of trade areas, and underestimate the importance of good locations. 
Thus, the review of the literature illustrates that most of the studies on retail potential were carried out in developed countries. This present study attempts to investigate the retail potential of districts in Istanbul which do not have any shopping mall. Background information about the growth of population and service sector and distribution of shopping malls according to the concentric rings are given and then estimates the retail potential of the districts by the use of a gravity model. The final section is devoted to a conclusion and suggestions for further research.

\section{BACKGROUND TO RETAIL MARKET OF ISTANBUL}

Istanbul, the largest city of Turkey with a population in excess of $10 \mathrm{~m}$ and its strategic location between Europe and Asia, is the country's most important socio-economic and cultural centre (Figure 1). The aggregated market in the Istanbul Metropolitan Area is the largest in Turkey. Most of the headquarter offices, the majority of the financial institutions and a dominant share of trade and business activities are located in Istanbul due to its international relationships, and thus it reflects all aspects of the evolution of commercial activity in the country. ${ }^{37}$ The wholesale and retail trade components, together comprising over one-fourth of the total employment, have traditionally been the strongest sector in Istanbul's economy. Retailing is the most successful developing market among the other real estate markets. The prime yield of the retail sector in Istanbul is an average of 9.0-11 per cent ${ }^{38}$ compared to 6.0 per cent in Rome, 4.5 per cent in London ${ }^{39}$ and 4.0 per cent in Paris. ${ }^{40}$ Rental levels in Istanbul's shopping centres currently range from \$243-1977 annually, ${ }^{38}$ compared to an average of $\$ 9250$ for London, $\$ 1539$ for Rome ${ }^{39}$ and $\$ 11074$ in Paris. $^{41}$

Istanbul's tremendous growth after 1950s has affected socio-economic and cultural conditions, as well as the physical structure of the city. Istanbul's peripheral highways have had a significant impact on retail expansion patterns in the metropolitan area. The intersection of the highways appears to have attracted some retail and office space development as well as garden apartments. These mixed used complexes form the bases of new subcentres of the city. Although, in the 1970s, the historical Central Business District (CBD) of Istanbul started to decline as a result of the aforementioned suburbanisation movement, it began to recover after the 1980 s with the help of revitalisation projects. ${ }^{42,43}$

In 1984, the Turkish Government abolished its prohibitive approach to imports. Since then the country has achieved considerable progress in liberalising many of its product markets. ${ }^{3}$ Increasing exposure to other cultures stimulated the growth of a new consumer culture and lifestyle under the influence of global consumption patterns. ${ }^{5}$ Increasing car ownership, newly introduced credit cards, more international coverage on domestic television and more exposure to alternative lifestyles stimulated consumption in the shopping malls. People have adapted eagerly to the use of shopping malls, mainly due to modernity in these global spaces through consumption and leisure patterns provided by a more fashionable space than the traditional urban centres and the shopping streets. ${ }^{5}$ Although Istanbul has only 15 per cent of Turkey's population, it has 


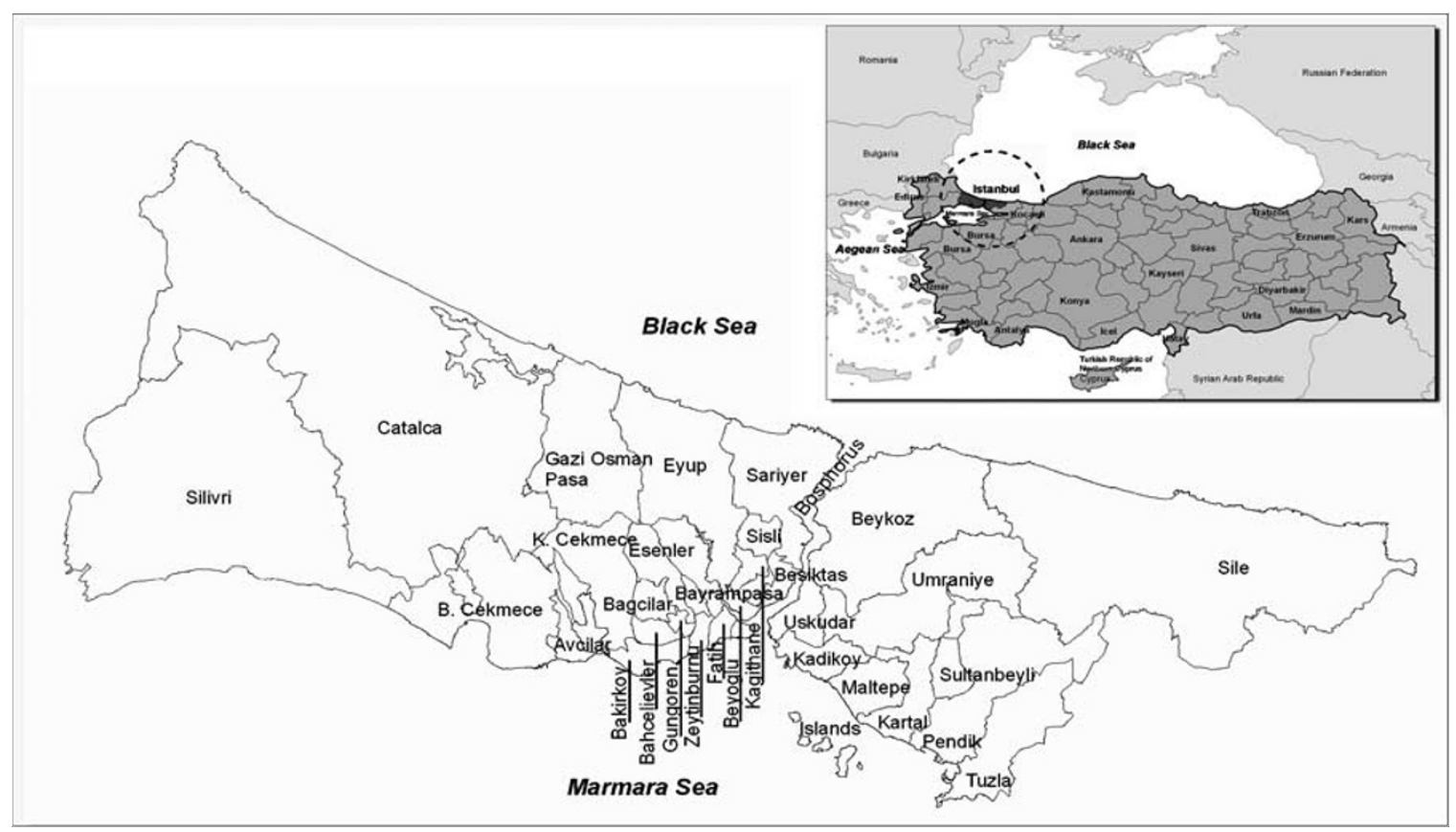

Figure I: Location of Istanbul in Turkey (upper right) and Districts of Istanbul (bottom)

34 per cent of shopping malls ${ }^{44}$ due to its economic superiority over the country and its greater exposure to globalisation.

Although the Istanbul Metropolitan Area has a complex structure, for market analytic purposes, it can be divided into three zones and the spatial distribution of shopping malls is illustrated according to concentric rings in terms of GIS techniques as follows (Figure 2). The historical core is up to $3 \mathrm{~km}$ and consists primarily of traditional retail strips, covered bazaars and passages and does not have any modern shopping mall.

The first ring is from 3 to $10 \mathrm{~km}$, which covers the area occupied by the city in the 1950 s before the commencement of rural migration. This zone is linked closely to the core and the periphery by subway, bus and ferry. This zone has 44 per cent of the city's gross domestic product (GDP), 37 per cent of population, 52 per cent of service sector, 43 per cent of retail employment and 51 per cent of leasable space of shopping malls. This zone also consists of attractive retail strip-corridors in addition to shopping malls associated with office and residential developments and serving large market areas.

The second ring is taken as the peripheral area beyond the first ring and it has the 42 per cent of the city's GDP, 60 per cent of the population, 37 per cent of the service sector, 42 per cent of retail employment and 49 per cent of leasable space of shopping malls. Thus, this analysis illustrates that the second ring has less shopping mall space than the first ring with respect to its population. In other words, nine districts that do not have any mall are located in this zone. The existing shopping malls constitute the base for new subcentres supplied by the peripheral highways and mixed used development. With this new pattern of urban growth, shopping centres are coming into being by reason of the increase in suburban population and the resultant increase in purchasing power 


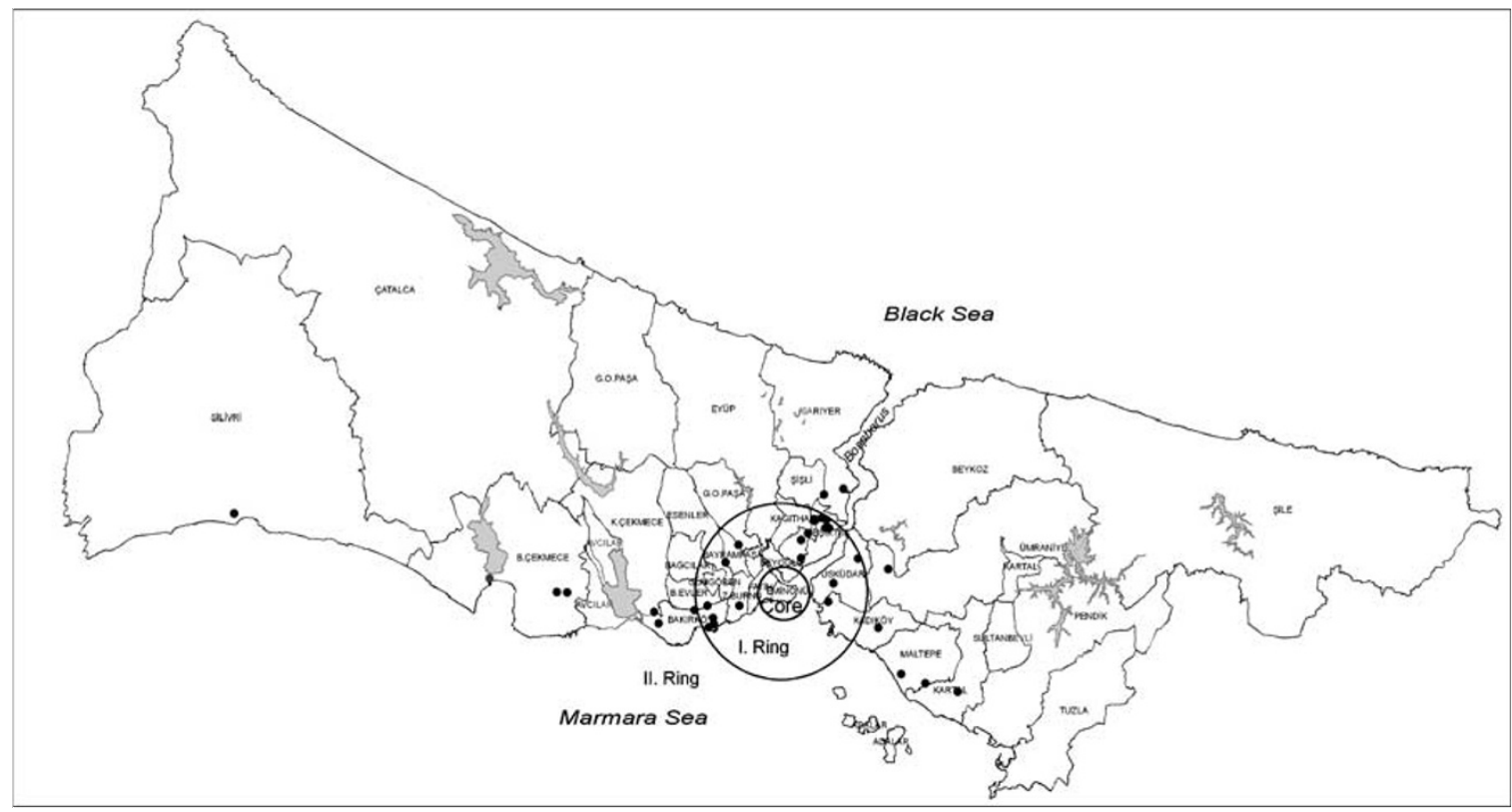

Figure 2: Spatial distribution of existing shopping malls (black dots) in Istanbul. Source: Istanbul Metropolitan Municipality, City Planning Directorate, 2006

located there rather than by reason of any flight of downtown business. The impact of the increase in the car numbers makes possible a redistribution of expanded commercial and industrial activity over a greater area surrounding the metropolitan core. Within this large spectrum of retail distribution, the retail structure of Istanbul is divided between a small number of affluent subcentres due to the concentration of income and extensive areas served by traditional shopping streets and markets. ${ }^{45}$

With the increase in car ownership, the growth of suburban population, the growing desire for western-style products and demographically prosperous and western-aware population, the number of large shopping malls in Istanbul continues to increase. With this process international retailers have started to enter the market and are working in partnership with successful Turkish developers.

The French companies Carrefour and Continent introduced the first hypermarket operations at the beginning of the 1990s with the Metro Group following shortly behind them. Both companies have liaised with national players who are more familiar with the local market and practices. Carrefour has entered the market through a joint venture with Sabanci Holding and Metro through an alliance with Tepe Group. Bauhaus opened the first nonfood out-of-town DIY and furniture superstores, and Swedish retailer IKEA entered the market in 2005. In addition, big name fashion retailers such as Armani, Benetton, Cacharel, Camper, Debenhams, Diesel, DKNY, Escada, Gas, Gucci, Hugo Boss, Lacoste, Laura Baresse, Levi's, Louis Vuitton, Mango, Marks \& Spencer, Massimo Dutti, More \& More, Naf Naf, Premaman, Versace, Stefanel, Nike, Roberto Cavalli, Tods, Tommy Hilfiger, Top Shop, Zara are the other foreign companies currently trading in Istanbul. ${ }^{38}$ 
Recently opened shopping centres (Cevahir, Tower and Kanyon) have accelerated the newcomer brands. Tchibo, Laura Baresse and Debenhams, Harvey Nichols, Barnes \& Nobel, Hakkasan, Intersport, Conbipel, Douglas, Furla, Caesar Paciotti, Pilgrim, Natalys and Segafredo are examples of brands that have recently entered the market. ${ }^{38}$

\section{RETAIL POTENTIAL OF THE ISTANBUL'S DISTRICTS}

The urban form and shopping malls have influenced each other's development interactively with respect to the development of subcentres throughout the city supported by side functions, modern housing projects, office buildings, expressways and subways. The determination of the retail potential of the districts is an important subject for the success of the new shopping malls and to protect the existing ones as well as an efficient development of the urban structure.

The locational decision is the most complex and critical decision a retailer can make. A superior decision facilitates access to existing customers, serves as one mechanism for capturing sales from competitors and enhances visibility to those (potential customers) traveling through the area. ${ }^{10}$ Site location analysis, particularly with the increased availability of computer-based techniques, can provide invaluable information to assist retail management with its decision-making process. ${ }^{31}$

Previous models take into consideration income, population and demographic characteristics in order to investigate retail potential of areas. Ingene and $\mathrm{Yu}^{46}$ observe that sales per capita and total sales are functions of income per capita and total income, respectively. There are also studies which investigate consumer characteristics, including population age, education, occupation and ethnicity to determine consumer behaviour. ${ }^{5,47}$

In this study, the Huff model is used to determine the retail potential of 13 districts that do not yet have a shopping mall (Table 1). Two historical districts with extensive traditional malls and shopping streets and a resort islands district are not included in the analysis. The size of the existing malls and GDPs of the districts are given in Table 1. The location of the existing malls is illustrated by the use of GIS techniques in Figure 2. The size of each new shopping mall is taken as $50,000 \mathrm{~m}^{2}$ in the calculation of the retail potential of the districts. The purchasing power of the districts is taken as 20 per cent of the GDP of the districts. The formulation of retail potential of districts is given as follows:

$$
S_{i j}=C_{j} \frac{\frac{F_{j}}{d_{i j}^{\alpha}}}{\sum_{i=1}^{n} \frac{F_{j}}{d_{i j}^{\alpha}}}
$$

where $S_{i j}$ is the retail potential attracted from district $i$ to shopping mall $j$ $C j$ is the purchasing power of district $j, F_{j}$ is the surface area of shopping mall $j$ and $d_{i j}^{\alpha}$ is the distance between district $i$ and shopping mall $j$. 
Table I: Shopping mall gross leaseble area and GDP of the districts

\begin{tabular}{|c|c|c|}
\hline Districts & Gross leaseble area $\left(\mathrm{m}^{2}\right)^{44}$ & GDP (2003) (\$million) ${ }^{48}$ \\
\hline \multicolumn{3}{|l|}{ I. Ring } \\
\hline Sisli & 155,300 & 183.33 \\
\hline Besiktas & 112,089 & 85.56 \\
\hline Kadikoy & 84,250 & 171.11 \\
\hline Uskudar & 38,500 & 65.19 \\
\hline Zeytinburnu & 29,048 & 101.85 \\
\hline Bayrampasa & 11,079 & 73.33 \\
\hline Fatih & ND & 87.59 \\
\hline Gungoren & ND & 48.89 \\
\hline Kagithane & ND & 50.93 \\
\hline Eyup & ND & 36.67 \\
\hline \multicolumn{3}{|l|}{ 2. Ring } \\
\hline Bakirkoy & 109,407 & 177.22 \\
\hline Maltepe & 60,500 & 28.52 \\
\hline B. Cekmece & 58,031 & 38.70 \\
\hline Umraniye & 48,930 & 48.89 \\
\hline Silivri & 45,000 & 16.30 \\
\hline Kartal & 39,690 & 71.30 \\
\hline Bahcelievler & 17,500 & 55.00 \\
\hline G.O.P. & 14,000 & 67.22 \\
\hline Sariyer & 11,000 & 26.48 \\
\hline K. Cekmece & 7,500 & 61.11 \\
\hline Avcilar & ND & 59.07 \\
\hline Bagcilar & ND & 50.93 \\
\hline Beykoz & ND & 24.44 \\
\hline Catalca & ND & 16.30 \\
\hline Esenler & ND & 24.44 \\
\hline Pendik & ND & 38.70 \\
\hline Sultanbeyli & ND & 28.52 \\
\hline Sile & ND & 8.15 \\
\hline Tuzla & ND & 14.26 \\
\hline
\end{tabular}

$\mathrm{ND}$, no data available.

The results of the model are given in Table 2 and represented by the use of GIS techniques in Figure 3. According to the results, the districts that are centrally located and close to the higher income districts have higher potential than the peripheral districts such as Gungoren, which has $\$ 28.60 \mathrm{~m}$ retail potential. Fatih has the second highest retail potential, but no vacant plot is available for a shopping mall. In Fatih, traditional street retailing is set to continue to dominate the characteristic of the retail industry in the future. Bagcilar, which is an adjoining district to Gungoren, has the third highest potential with $\$ 17.56 \mathrm{~m}$. In the case of building a shopping mall in either Gungoren or Bagcilar, a negative impact would be experienced in the peripheral districts such as Buyukcekmece, Kucukcekmece, Sariyer, Silivri whereas a positive impact would be experienced in central districts such as Besiktas, Sisli, Bayrampasa. In addition, adjoining districts such as Bakirkoy, Bahcelievler and Zeytinburnu are likely to be affected positively too.

According to the figures given in Table 2, Gungoren with its adjoining districts of Esenler and Bagcilar has a retail potential of $\$ 58.50 \mathrm{~m}$ justifying the building of one shopping mall. Since the model did not take into account new residential developments, the retail potential is expected to be higher than this figure. 
Table 2: Retail potential of the districts for the proposed shopping malls with $50,000 \mathrm{~m}^{2}$

\begin{tabular}{ll}
\hline Districts & Retail potential (\$million) \\
\hline Gungoren & 28.60 \\
Fatih & 21.60 \\
Bagcilar & 17.56 \\
Kagithane & 17.40 \\
Avcilar & 14.92 \\
Esenler & 12.34 \\
Pendik & 11.38 \\
Tuzla & 11.36 \\
Eyup & 10.90 \\
Sultanbeyli & 9.92 \\
Beykoz & 8.75 \\
Catalca & 7.82 \\
Sile & 5.10 \\
\hline
\end{tabular}

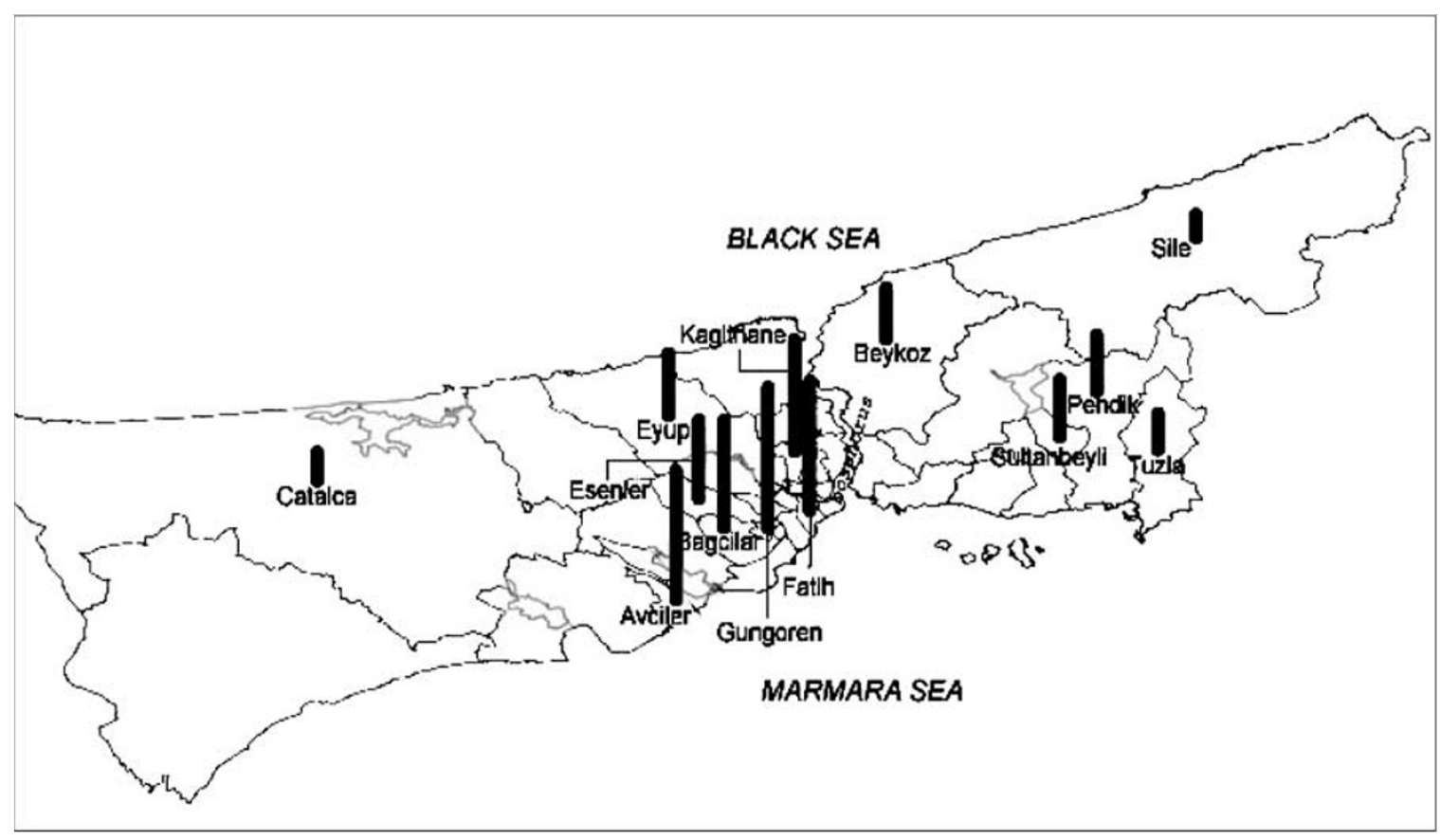

Figure 3: Retail potential of districts of Istanbul. The size of the bars illustrates the retail potential of the districts. The higher bar shows the higher district's potential as dollars

The districts with higher retail potential provide opportunities at the national and international level for the success of new retail investments and more efficient development of the urban retail structure. In order to attract shopping mall developments to peripheral districts with less economic potential, it is necessary to provide additional support through a mixed use approach which the Istanbul Municipal Government is planning to do so. At the same time, it is expected that recent upper income housing development projects in the periphery will encourage further shopping mall construction and stimulate new subcentres development. 


\section{CONCLUSION}

The 1990s has witnessed the increase in the number of shopping malls in Istanbul primarily as a result of globalisation, liberalisation of economy and increasing income in Istanbul. Moreover, the consumption behaviour of the inhabitants of Istanbul makes a good reason for the success of this type of development. Shopping malls provide modern colourful, climate controlled and guarded consumption and leisure spaces, which attract customers from different income and age groups of Istanbul's society. Istanbul with its large population and its rapidly growing retail market offers a great potential for the new investors. Istanbul is and will continue to be the national and regional hometown of multinational companies from all sectors. Since income is concentrated within a small number of extremely wealthy districts, retail structure is divided between a small number of shopping malls, which are located in affluent subcentres and extensive areas served by traditional markets.

Continuous expansion of the city, the development of a multicentre urban structure, the decaying inner city, changes in population density and lifestyles have affected the spatial distribution of needs, purchasing power and demand for retail facilities. Despite the growing number of shopping malls, there are still areas in the city that are under supplied by the retail facilities. There are 33 shopping malls that are located in 16 districts out of 32 districts of Istanbul. The spatial distribution of shopping malls is analyzed according to concentric rings of the city. Although the first ring has only 37 per cent of the city population, it has 49 per cent of the number of shopping malls. The second ring which accommodates 60 per cent of the population of the city, however, has only 52 per cent of the number of shopping malls. It is a crucial task to estimate the retail potential of the districts that do not have any shopping mall in order to maximise the performance of the new malls. At the same time, it is important to preview the shopping malls location since they increase land values in their surrounding areas and they stimulate the transformation of urban structure. Thus, this study estimates the retail potential of these districts by the use of a gravity model, which takes into consideration GDP of the districts, surface areas of the existing and proposed shopping malls and distances between them. Gravity models have been applied to the retail context extensively. According to the results of the analysis, the districts are ranked with respect to their retail potential. As expected, centrally located areas in close distance to the high income districts have most potential and provide great opportunities for national and international real estate investors. Thus, as in the previous studies, higher income and accessibility are the most important factors affecting the retail potential of the districts. The results of the study can be useful for retailers, real estate developers, urban planners, transportation planners and policy makers.

Further research on emerging consumption and leisure patterns with respect to different socio-economic and cultural groups and their spatial implications is expected to contribute for the development of more comprehensive retail potential models. 


\section{Acknowledgements}

We thank Ian A. Elliott for editing this paper.

\section{References}

1. Cohen, L. (1996). From town center to shopping center: the reconfiguration of community marketplaces in postwar America. The American Historical Review 101(4), 1050-1081.

2. Keyder, C. \& Oncu, A. (1994). Globalization of a third world metropolises: Istanbul in the 1980s. Review 17, 383-421.

3. Tokatli, N. \& Eldener, Y. (2002). Globalization and the changing political economy of distribution channels in Turkey. Environment and Planning A 34, 217-238.

4. Tokatli, N. \& Boyaci, Y. (1999). The changing morphology of commercial activity in Istanbul. Cities 16(3), 181-193.

5. Erkip, F. (2005). The rise of the shopping mall in Turkey: the use and appeal of a mall in Ankara. Cities 22(2), 89-108.

6. Leishman, C. (2003). Real Estate Market Research and Analysis, Palgrave Mc Millan, New York.

7. Okoruwa, A. A., Nourse, H. O. \& Terza, J. V. (1994). Estimating sales for retail centers: an application of the poisson gravity model. The Journal of Real Estate Research 9(1), 85-97.

8. Serra, D. \& Colomé, R. (2001). Consumer choice and optimal locations models: formulations heuristics. Papers in Regional Science 80(4), 439-464.

9. Reilly, W. J. (1931). The Law of Retail Gravitation, William J. Reilly Co. New York.

10. Schmidt, C. G. (1988). Retail trade area analysis: approaches and techniques, in Clapp, J.M., Messner, S.D. (eds.) Real Estate Market Analysis: Methods and Applications, Praeger, New York.

11. Fotheringham, A. S. (1988). Market share analysis techniques: a review and illustration of current US practice, in Wrigley, N. (ed.) Store Choice, Store Location and Market Analysis, Chapman \& Hall. Andover, Hants, UK, Routledge.

12. Ghosh, A. \& McLafferty, S. L. (1987). Location Strategies for Retail and Service Firms, DC Heath, Lexington, MA.

13. Rogers, D. S. (1984). Modern methods of sales forecasting: gravity models in Davies, R.I., Rogers, D.S. (eds.) Store Location and Store Assessment Research, John Wiley, Chichester, Sussex, UK.

14. Huff, D. L. (1966). A programmed solution for approximating an optimum retail location. Land Economics 42(3), 293-303.

15. Epstein, B. J. (1984). Market appraisals in Davies, R.I. \& Rogers, D.S. (eds.) Store Location and Store Assessment Research, John Wiley, Chichester, Sussex, UK.

16. Lakshmanan, T. R. \& Hansen, W. G. (1966). A retail market potential model. Journal of the American Institute of Planners 13, 134-143.

17. Roy, J. R. \& Thill, J. C. (2004). Spatial interaction modeling papers. Papers in Regional Science 83, 339-361.

18. Berry, B. J. L. \& Parr, J. D. (1988). Market Centers and Retail Location: Theory and Applications, Prentice-Hall, Englewood Cliffs, NJ, USA.

19. Craig, C. S., Ghosh, A. \& McLafferty, S. (1994). Models of the retail location process: a review. Journal of Retailing 60, 5-35.

20. Rijk, F. J. A. \& Vorst, A. C. F. (1983). On the uniqueness and existence of equilibrium points in an urban retail model. Environment and Planning A 15, 475-482.

21. Muench, T. J. (1988). Quantum agglomeration formation during growth in a combined economic gravity model. Journal of Urban Economics 23, 199-214.

22. Beaumont, J. R. (1988). Store location analysis: problems and progress in Wrigley, N. (ed.) Store Choice, Store Location and Market Analysis, Routledge, Chapman \& Hall. Andover, Hants, UK.

23. Sleight, P. \& Leventhal, B. (1989). Applications of geodemographics to research and marketing. Journal of the Market Research Society 31, 75-101.

24. Serra, D. \& Revelle, C. (1994). Market capture by two competitors: the preemptive location problem. Journal of Regional Science 34(4), 549-561.

25. Serra, D. \& Revelle, C. (1996). Competitive location on networks in Drezner, Z. (ed.) Facility Location: A Survey of Applications and Methods, Springer, Berlin.

26. Drezner, T. (1998). Location of multiple retail facilities with limited budget constraints-in continuous space. Journal of Retailing and Consumer Spaces 5(3), 173-184.

27. Jayet, H. (1990). Spatial search processes and spatial interaction: 1. Sequential search, intervening opportunities and spatial search equilibrium. Environment and Planning A 22, 583-599. 
28. Williams, H. C. W. \& Kim, K. S. (1990). Location-spatial interaction models: 3. Competition between organizations. Environment and Planning A 22, 1281-1290.

29. Roy, J. R. (1990). Spatial interaction modeling: some interpretations and challenges. Environment and Planning A 22, 712-716.

30. Brown, S. (1992). The wheel of retail gravitation? Environment and Planning A 24, 1409-1429.

31. Moutinho, L., Curry, B. \& Davies, F. (1993). Comparative computer approaches to multi-outlet retail site location decisions. The Service Industries Journal 13(4), 201-220.

32. Roy, J. R., Smith, N. C. \& Xu, B. (2001). Simultaneous modelling of multi-purpose multi-stop activity patterns and quantities consumed. Journal of Geographic Systems 3, 303-324.

33. Mushinski, D. \& Weiler, S. (2002). A note on the geographic interdependencies of retail market areas. Journal of Regional Science 42(1), 75-86.

34. Benoit, D. \& Clarke, G. P. (1997). Assessing GIS for retail location planning. Journal of Retailing and Consumer Services 4(4), 239-258.

35. Yang, Z. Z. (2002). Microanalysis of shopping center location in terms of retail supply quality and environmental impact. Journal of Urban Planning and Development 128(3), 139-149.

36. Lee, M. L. \& Pace, R. K. (2005). Spatial distribution of retail sales. The Journal of Real Estate Finance and Economics 31(1), 53-69.

37. Dokmeci, V. \& Berkoz, L. (1994). Transformation of Istanbul from a monocentric to a polycentric City. European Planning Studies 2, 193-205.

38. Kuzey Batý Real Estate Services (2006). The Retail Property Market, Country overview', Istanbul.

39. GVA Williams Real Estate Service (2006). Europe, market statistics, year-end 2005, GVA Williams. http://www.gvaworldwide.com/x906.xml?m=F\&C=USD Accessed 10th August 2006.

40. PPR (Pinault-Printemps-Redoute) Group (2003). Press release. Available from http://www.ppr. Com/DataUploadFiles/PUBLICATIONS/7278/CA\%20T203\%20VE.pdf Accessed 10th August 2006.

41. CB Richard Ellis (2006). Global Market View', CBRE, Los Angeles, USA.

42. Ozus, E. \& Dokmeci, V. (2005). Effects of revitalization in historical city center of Istanbul. International Real Estate Review 8(1), 144-159.

43. Dokmeci, V., Altunbas, U. \& Yazgi, B. (2006). Revitilization of the main street of a distinguished old neighbourhood in Istanbul. European Planning Studies, in press.

44. Shopping centers and Retailers Association (2005). The list of gross leaseble area of shopping mall in Turkey, Istanbul.

45. Dokmeci, V., Yazgi, B. \& Ozus, E. (2006). Informal retailing in a global age: the growth of periodic markets in Istanbul, 1980-2002. Cities 23(1), 44-55.

46. Ingene, C. \& Yu, E. (1981). Determinants of retail sales in SMSAs. Regional Science and Urban Economics 11, 529-547.

47. Evans, K. T., Christiansen, T. \& Gill, T. D. (1996). The impact of social influence and role expectations on shopping center patronage,. Academy of Marketing Science Journal 24(3), 208-218.

48. State Statistical Institute (1996). Gross domestic product by districts State Statistical Institute. http://www.die.gov.tr/TURKISH/SONIST/GSYIH/241097t1.htm Accessed 10th August 2006. 